\title{
Science in School: Transforming K-12 Outreach Through Scientist Teacher Partnerships
}

\author{
Brian Abramowitz ${ }^{1,2,3}$, Megan Ennes ${ }^{1,2}$, Stephanie Killingsworth ${ }^{1,2}$, Pavlo D. Antonenko ${ }^{2,3}$, Bruce MacFadden ${ }^{1,2}$, and \\ Alan Ivory ${ }^{1,2}$ \\ ${ }^{1}$ Florida Museum of Natural History, ${ }^{2}$ Thompson Earth Systems Institute, and ${ }^{3}$ College of Education, University of Florida, Gainesville, FL
}

Keywords: K-12 outreach, scientist teacher partnerships, broader impacts, scientist in schools, Earth systems, nature of science, Florida, public schools

Publication Date: December 8, 2021

DOI: https://doi.org/10.15695/jstem/v4i1.14

\begin{abstract}
The Scientist in Every Florida School (SEFS) program was started in 2019 with a long-term vision to connect Earth systems scientists with public K-12 schools in Florida and therefore create long-term scientist-teacher partnerships. SEFS fulfills teacher requests to create personalized, meaningful, and impactful experiences to support teacher pedagogy and student learning. As part of our mission, we have a focus on mainstream, particularly Title I, schools and are committed to working with at-risk teachers. The major components of our program include scientist-teacher partnerships, focused professional development workshops on Florida's Earth systems (air, water, land, and life), classroom visits, and other web-based activities. Although still only in its first few years, the project and its more than 600 scientists have a wide reach with over 850 teachers and 53,000 students. Notably, the programs were delivered virtually in the 2020-2021 school year reaching nearly $60 \%$ of Florida's 67 counties. In this article, we describe our programmatic features and provide recommendations for others to implement similar programs. One recommendation, which has contributed largely to the program's success, is to invest in outreach coordinators. By doing so, scientists and teachers benefit by having a more streamlined process for classroom visits and teacher workshops.
\end{abstract}

\section{INTRODUCTION}

Florida is on the front lines of massive Earth systems changes that are threatening the environment, economy, and our way of life. Earth systems refer to the interaction of air (atmosphere), water (hydrosphere), land (geosphere), and life (biosphere), and how humans impact them. Current research indicates that educating the next generation about societally relevant issues such as climate change is vital for developing a scientifically literate public empowered to take action regarding these issues (e.g., Hahn, 2021; Peterson et al., 2019). The emphasis on K-12 learners will hopefully lead to greater change because they are likely more receptive than adults to learning about current Earth systems topics (Ennes, 2021; Kahan, 2012; Stevenson et al., 2014). Unfortunately, science often takes the backseat in the K-12 school system, despite its contribution to social and economic progress (Marincola, 2006). The marginalization of science instruction is particularly true in elementary schools where some teachers lack the background, confidence, or mandate to teach science (Menon and Sadler, 2016; Plumley, 2019).

The Scientist in Every Florida School (SEFS) program was developed in the fall of 2019 to help support high-quality science teaching through scientist-teacher partnerships. The program was initiated when the University of Florida's (UF) Thompson Earth Systems Institute (TESI) received funding from the UF President's office along with support from other stakeholders to fund a pilot program for four years. This pilot program set the foundation for our "Moonshot" initiative: the "Scientist in Every Florida School" program (Spence, 2019). The concept of a "moonshot" comes from President John F. Kennedy, who in the early 1960s presented a lofty goal--to put an astronaut on the moon by the end of that decade (Brinkley, 2019; Oliphant 2019). This was a seemingly unattainable challenge because the science and technology infrastructure of the time was not prepared to put a person on the moon. Thus, during the remainder of the 1960s, many aspects of Kennedy's goal were achieved through scientific and technological innovations. In the same vein, our SEFS program seeks to provide innovation and develop new ways and best practices for reaching Florida schools, their teachers, and students. The mission of SEFS is to engage Florida's K-12 students and teachers in cutting-edge science in a way that provides role models and experiences to inspire the 
future stewards of our planet. Scientist role models include graduate students, post-doctoral researchers, university faculty, and industry partners at local, state, and federal agencies.

Funding agencies expect scientists to engage authentically with society and, in doing so, make lasting impacts on the future. For example, the National Science Foundation requires "Broader Impacts" plans in grant proposals. Likewise, many scientific institutions expect their scientists to conduct outreach activities (MacFadden, 2019). Earth systems scientists interested in sharing their research with K-12 communities in Florida may collaborate with SEFS to reach their target audiences.

By partnering with SEFS for their Broader Impacts components, scientists gain access to a network of K-12 schools, teachers, and district leaders who have come to trust SEFS's work. The team is composed of former K-12 educators who understand the unique and specific needs of classrooms and are well-versed in state learning standards. When a scientist partners with SEFS, the team will not only help match the scientist with the K-12 audience but will also help scientists articulate their research expertise in a way that is understandable, engaging, and aligned with existing curricula.

Benefits to Teachers/Scientists. Evidence indicates that participation in scientist-teacher partnerships can have positive effects on the scientists, teachers, and students (e.g., Brown et al., 2014; Herrington, et al., 2016; Shein and Tsai, 2015; Ufnar et al., 2017, 2018). One study found that participation in such a program resulted in positive belief, value, and attitude changes for teachers regarding their ability to teach inquiry-based science in their classrooms and their schools (Herrington et al., 2016). Another study found that scientist-teacher partnerships not only increased the teachers' ability to teach via inquiry but also increased their confidence and content knowledge (Ufnar et al., 2017). The same trends have also been found globally as a study in Taiwan found that participation increased teachers' levels of content knowledge as well as their pedagogical content knowledge (PCK). Similarly, the scientist felt they had a better understanding of how students learn, what is taught in schools, and PCK (Shein and Tsai, 2015). Participation in our program helps teachers feel more confident teaching content after talking to an expert. Additionally, students feel inspired by the role models who visit their class, become more aware of Florida's environmental changes around them resulting from climate change, and what can be done about these issues.

While many studies focus on the impacts of scientist-teacher partnerships on students and teachers, there are very few that focus on the impacts of such partnerships on scientists (e.g., Tanner, 2000; Ufnar et al., 2017). A study of 34 scientists found that the scientists benefited as profession- als, university educators, and individuals (Tanner, 2000). Scientists benefit professionally because of scientist-teacher partnerships through their ability to engage with their colleagues in new ways, to develop new skills that are useful in their line of work, to reflect on their understanding of or excitement related to science, and to consider new careers (Tanner, 2000). As future educators, scientists learn to explain content more simply, learn about pedagogy related to teaching science, and put science communication strategies into practice. Scientists also learn more about teachers and students in K-12 schools through scientist-partnerships and conclude that they can act as student role models. Finally, as individuals, scientists personally increase their self-efficacy, engage in community service, and enrich their lives (Tanner, 2000). Similarly, the study by Ufnar and colleagues (2017) found that participation allowed scientists to gain skills related to communication, mentoring, and teaching as well as allowing them to serve as student role models.

Leveraging these benefits to all involved, the goals of the SEFS program are to build long-term collaborative relationships between teachers and scientists, introduce K-12 students to scientists encompassing a wide range of Earth systems careers, and increase the integration of current scientific research and big data into classroom lessons. To achieve these goals, we coordinate virtual and in-person scientist visits to schools across Florida. The scientist visits serve to engage students with real-world Earth systems science and increase interest in related science, technology, engineering, and math (STEM) careers. Although similar programs exist across the nation, such as Bay Area Scientists Inspiring Students (BASIS, n.d.), Skype a Scientist (2021), and Letter to a Pre-Scientist (n.d.), SEFS is distinguished by its unique statewide focus that prioritizes long-term relationships through personalized interactions via scientist-teacher partnerships, customized school visits, and an emphasis on public schools. We place priority on schools that are designated as Title 1, which is a federal program that provides financial assistance to schools for children from low-income families to help ensure that they meet challenging state academic standards (NCES, 2021). In this article, we describe our program and what we have learned so far as we move forward with our decadal vision of impacting Florida science education in public schools.

Vision and Rationale. As the name denotes, over the next decade, the SEFS program seeks to meet its long-term goal to have scientists visit, reach, or impact every K-12 public school in Florida at least once a year. With more than 3,000 public schools in the 67 Florida counties (School, n.d.), SEFS's mission is indeed a daunting task, but it remains our aspirational vision--one by virtue of its title that is easily communicated and quickly grasped by stakeholders.

In the preceding paragraph, we use three terms: visit, 
reach, and impact, each of which has a specific meaning. We frequently use these as activity metrics in the context of the SEFS program. A visit is an event in which a scientist goes into a classroom, either in-person or virtually. We typically gather data on the number of teachers and students, as well as which scientists participated at a particular visit. Reach is used to quantify the number of teachers or students who participated in the visit. For example, if SEFS scientists interacted with 70 teachers during a particular professional development (PD) session, that number of attendees would have been reached through the activities. In terms of efficacy, however, neither visit nor reach allows us to understand what our audiences learned or how they benefited from our SEFS activities. In contrast, impact is a term reserved to describe how we improved engagement, understanding, and/or learning. We assess impact via evaluation, primarily through teacher surveys, but qualitative feedback from participants, e.g., open-ended survey questions or unsolicited email responses. In our program, impact is the best indicator of the efficacy of our programs and activities.

Our program activities ramped up significantly in July of 2019 with the hiring of two K-12 SEFS coordinators and our first annual summer PD. Between July 2019 and February 2020, we developed a comprehensive slate of in-person classroom visits, district-focused PDs, and web-based activities. During the initial phase, we felt that our in-person classroom activities were a hallmark of our program. However, in early 2020, with the onset of COVID-19, physical schools closed and we quickly pivoted to fully virtual programming for all of our activities. Given what we have learned during COVID-19, our transformation to mostly virtual programming allowed us to both scale up our programming and economize our efforts, for example, the cost of travel was greatly reduced.

Conceptual Framework. Today, K-12 science education in the U.S. is informed by the Framework for K-12 Science Education released by the US National Research Council in 2012 (National Research Council, 2012). The Framework is often referred to by K-12 educators and researchers as the 3D science learning framework because it conceptualizes $\mathrm{K}-12$ science education as consisting of three core dimensions: a) STEM practices, b) crosscutting concepts, and c) disciplinary core ideas. Furthermore, while science teachers have numerous resources such as curricula and textbooks for incorporating crosscutting concepts (e.g., structure and function) and disciplinary core ideas (e.g., photosynthesis) in their instruction, integration of authentic scientific practices in science instruction presents more of a challenge. The main reason for the difficulty in implementation is that until recently teacher preparation programs, curricula, and methods have focused primarily on the dimensions of disciplinary core ideas and crosscutting concepts, whereas the practices of doing science and STEM more generally were left largely unaddressed (National Research Council, 2012, 2014).

The SEFS program addresses the issue of improving science teachers' understanding and integration of STEM practices in their instruction by matching them with scientists who can demonstrate in K-12 classrooms not only the science they do and why but also how they go about doing it, making clear the tacit STEM practices scientists use to address important societal issues. The focus on science as a set of core STEM practices is particularly important now when many of these fields rely heavily on technology, mathematics, and engineering. For example, paleontology organically integrates concepts and content from biology, environmental science, geology, oceanography, and anthropology, while also harnessing the resources and tools available from other fields of STEM, including technology (e.g., big data in the cloud, 3D scanning; Callaway, 2011), engineering (e.g., advanced analytical 3D imaging, digital manufacturing; Hooper, 2013), and complex mathematical modeling, statistical algorithms, and machine learning (Elewa, 2011).

As a PD program at its core, SEFS uses best practices of teacher PD. Recent research found that effective PD has seven characteristics (Darling-Hammond et al., 2017). The characteristics focus on content, active learning, support for collaboration, models of effective practice, coaching and expert support, feedback/reflection, and a sustained duration (Bates and Morgan, 2018). Our program includes each of the components as described below (Figure 1).

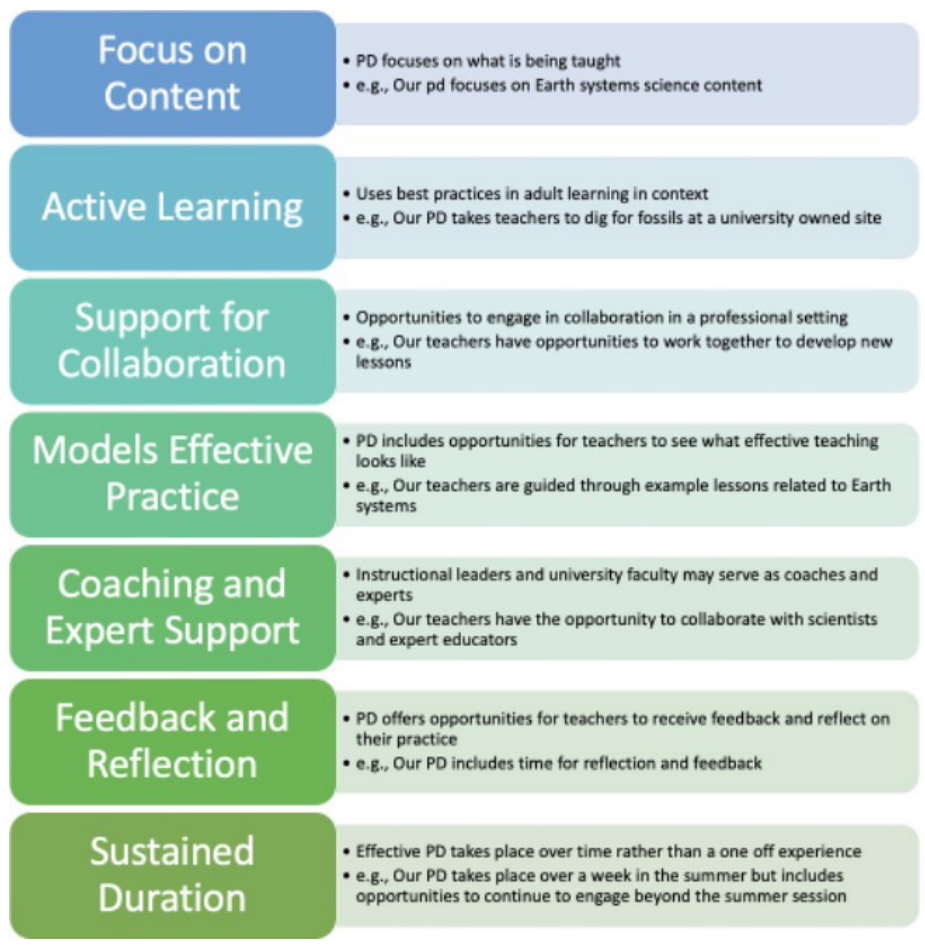

Figure 1. Characteristics of effective professional development for teachers as described by Bates and Morgan, 2018. 


\section{METHODS}

Focus on Content. Each year, the PD includes an area of content focus that relates to Earth systems science such as the biosphere (2019), nature of science (2020), and hydrosphere (2021). Content delivery includes keynotes and short presentations ("sparks") by experts in the respective fields, deeper dives into content with discussion, breakout sessions, and Q\&A with content experts, along with hands-on research experiences, field trips, and lesson collaboration. The K-12 education and outreach coordinators meet with the scientists to better prepare them for connecting with and teaching content to teachers. The meetings involve identifying and aligning relevant state standards related to their area of research.

Active Learning. To involve our participants in active learning, the PD model "engages educators using authentic artifacts, interactive activities, and other strategies to provide deeply embedded, highly contextualized professional learning" (Darling-Hammond et al., 2017, p. 7). In nonCOVID-19 years, PD includes authentic research experiences in the lab and field for teachers, field trips to nearby localities with expert guides, materials, and supplies for lessons to be implemented in the classroom, as well as ample time for small group and whole group discussion, collaboration, and reflection. For example, a group of teachers went to a UF fossil site where a fifth-grade teacher from Pensacola, Florida, discovered a five-million-year-old fossil horse tooth of scientific value (Burton, 2019). The newly uncovered fossil was added to the collections at the Florida Museum of Natural History, and as such, the teachers participated in authentic research discoveries. Since the onset of COVID-19 in March 2020, SEFS PDs have remained virtual and teachers and scientists connect remotely. If needed, supplies are shipped to the teacher for hands-on activities beforehand so they remain an integral part of the experience. The SEFS team iteratively reviews the workshop program and agenda and makes modifications based on survey feedback and debriefing notes.

Support for Collaboration. Collaboration allows teachers to break free from the structured environment of the classroom as well as to encourage change beyond an individual classroom (Darling-Hammond et al., 2017). To encourage collaboration, teachers work in groups with the support of their partner scientist throughout the week to develop lessons and extension activities to be taught in the classroom during the following school year. As part of the process, teachers are responsible for scheduling a scientist visit for their classrooms the following year and sharing artifacts with the SEFS team from the lesson implementation.

Collaboration elements are infused in the PD in several ways to make workshops feel like a safe and inclusive environment for teachers to feel comfortable as learners, to explore, and to ask questions. Teachers participate in a meet and greet before the workshop and regularly connect as a whole group as well as in smaller breakout groups during the week. They are also invited to participate in the SEFS Facebook group (a professional learning community and network of Florida teachers and scientists). Additionally, we encourage them to reach out to the SEFS team and their partner scientist at any time. Many teachers are invited back for subsequent PD opportunities and later teacher cohorts as teacher leaders. All of these collaboration opportunities allow for sustained social learning.

Models of Effective Practice. Modeling of activities, concepts, and the process of science are fundamental to our PD workshops. Each of the practices are integrated in a way that helps teachers to visualize how they can implement new strategies in their own classrooms (Darling-Hammond et al., 2017). The SEFS team models a related activity with the teachers who then take time to explore the activity themselves or in groups. Additionally, teachers come to the PD with their learning standards (Welcome to CPALMS, 2019) and pacing guides to best integrate the content learned. Collaboration with other teachers from the same grade bands and with scientists helps facilitate the creation of novel and innovative lessons and activities that incorporate the current research and content being taught with the standards taught in K-12 classrooms. The SEFS team often guides or supports teachers throughout the process. Teachers get to experience science first-hand which makes them not only more comfortable with the content but more confident and excited to teach it to their students.

Coaching and Expert Support. Experts have an important role in guiding and facilitating teachers' learning as it relates to their classroom practice (Darling-Hammond et al., 2017). Our program model relies on expert educators as facilitators and role model science experts to deliver current scientific research and understanding in a way that is accurate and trustworthy. Both teachers and students benefit from the role model interactions to create rich learning opportunities and to inspire the next generation of Florida's environmental stewards. District leaders often participate in the SEFS PDs as well so that they can provide additional support and feedback to their teachers who attend.

Feedback and Reflection. Effective PD allows teachers opportunities to engage in reflection, receive input related to their practice, and make changes as needed (Darling-Hammond et al., 2017). To address this need, the PD agenda has reflective time built into each day. This dedicated time helps the participants gain valuable feedback and for program organizers to gauge the teachers' level of understanding and aids in pacing as well as the depth and breadth of content delivery at the PD. 
Sustained Duration. Best practices in teacher PD underline the importance of sustained engagement between the teachers through multiple opportunities to learn about the content (Darling-Hammond et al., 2017). In addition to the weeklong PD experience, teachers who participate frequently remain engaged in additional PD opportunities. They typically apply to attend subsequent workshops, make multiple scientist requests for virtual and physical classroom visits throughout the year, and frequently attend the SEFS livestream programming. Teacher surveys have provided feedback to the team that teacher participation has sharpened their understanding of content, provided new ideas for lessons, and perhaps most importantly, has re-energized them to teach.

\section{STRATEGIC COMPONENTS AND GOALS}

Through formal strategic planning, we have identified several related goals for the SEFS program that, taken together with the overall vision, comprise the unique scope of our project.

Program Focus. SEFS is a program within TESI at the UF Florida Museum of Natural History. The mission of TESI is to enhance understanding of Earth systems including the atmosphere, hydrosphere, geosphere, and biosphere as well as the impact of humans on these systems. Simply put, we use the phrase "air, water, land, and life" as our thematic scope. When making decisions about programming and resource allocation, we are careful to focus only on Earth systems content domains. For example, we do not specifically focus on health-related content. Another theme of our programmatic activities includes the Nature of Science standards because they are ones that teachers are expected to teach and many Florida Standards align with Nature of Science concepts (Welcome to CPALMS, 2019). Repeated feedback from teachers indicates the need for students to better understand the process of science as it applies to different content domains.

Target Audience. SEFS is envisioned to serve mainstream public schools in Florida. Our rationale stems from the mission of UF as a land-grant, publicly funded university, and our general commitment to public education. With regard to specific activities and programs (e.g., school visits), we therefore tend not to focus on charter schools, private schools, and home-schooling, or the recent rise of K-12 learning pods (e.g., Sergent, 2020). However, when we have space available in our programs such as our teacher PD opportunities, we make them available to these groups. Likewise, some of our webinars have broader-intended audiences. For example, when we partner with informal learning institutions such as museums, nature centers, and botanical gardens, our virtual audience might include a broader K-12 composition as well as lifelong learners.

Scientist-Teacher Partnerships. Partnerships begin with teachers being introduced to their scientist collaborator as a result of attendance in a PD workshop or a requested classroom visit using a Google form. Oftentimes, the request form has been added to internal teacher portals or learning management systems (e.g., Google classroom) within many of the Florida school districts for accessibility. Our teacher-focused activities include classroom support via scientist visits and PD (Figure 2). Rather than a single interaction, SEFS aspires to build lasting relationships between the scientists and teachers. We envision that teachers will view the scientist as an available content resource provider and can call upon them as it makes sense. We believe that a strategy that prioritizes partnerships is not only important to the teachers, but, as other studies have shown, scientist-teacher partnerships also benefit the scientists (e.g., Komoroske et al., 2015; MacFadden, 2019; Tanner, 2000).

While scientists bring their content expertise to the partnerships, teachers can contribute their pedagogical knowledge and instructional skills. This specialized teacher input is what individualizes the lesson development process for his or her students. At the onset, teachers are given the space to share de-identified data with their scientist on how their students performed on various learning standards as indicated from learning assessments. SEFS teachers have mentioned that the curriculum can cover such a wide range of topics and it has been challenging to be an expert on all of them. The partnership intentionally pairs teachers and scientists through a "train the trainer" method to address student misconceptions and other needs. Further, the needs may extend to providing context around local environmental issues surrounding students and what can be done about them.

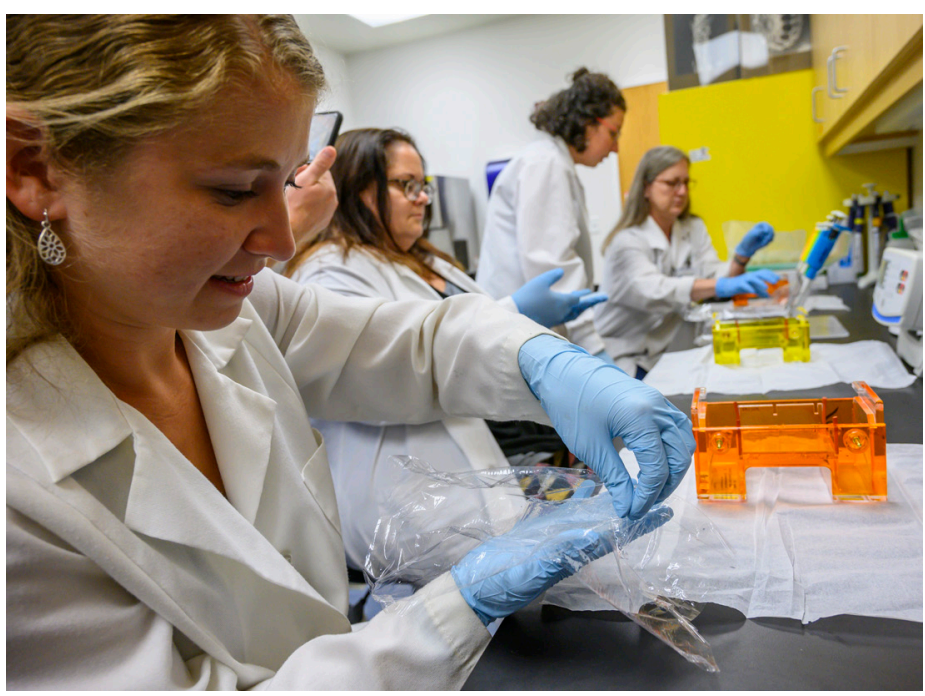

Figure 2. Scientists are mentoring teachers who take on the role of a scientist as they are provided an authentic lab experience. 
Teachers also provide scientists with a meaningful way to give back. For example, one of the SEFS scientists who specializes in meteorology informed the coordinators that he participates to be the role model he wished he had. Since he signed up, he has been heavily involved and had several outreach interactions with multiple schools in the surrounding area where he grew up. Additionally, teachers have reported that enrolling their students in citizen or community science projects have been ways for their students to be actively involved in real world current research. To encourage the longevity of the collaborations, coordinators routinely follow up with both parties via email to understand updates and how the SEFS team can best support them.

Diversity, Equity, Accessibility, and Inclusion (DEAI). Part of our program plan is to develop activities and reach schools that promote DEAI. In addition to DEAI being part of our TESI core culture, we consider DEAI in two specific ways: (a) within the K-12 districts that we have served so far, we place priority on Title 1 schools and their teachers, and (b) we deliberately select scientists who exemplify diverse and near-peer role models. Related to the latter, some teachers request that the scientists coming into their schools share similar backgrounds with the students.

At-Risk Teachers. At-risk teachers are those who are within their first five years in the profession and also mid-career teachers who are considering leaving the profession (Sparks, 2018). We identify at-risk teachers in our PD workshop application process. We specifically target those teacher applicants who fall within the at-risk category so that we can work with them to build their science content knowledge, hone their pedagogical skills, and fold them into our support network of teachers and scientists. Lack of support and feeling undervalued are two major indicators for why new teachers often leave the profession. Two aspects of all SEFS PD opportunities are that teachers and scientists complete classroom visits and that teachers receive a stipend for participation, which are ways the SEFS team works to ensure at-risk teachers feel both supported and valued. Retention of public-school teachers is widely recognized as a systemic challenge affecting the K-12 educational workforce throughout the U.S., and so too is the case in Florida (García and Weiss, 2016). For example, in January 2019, with half of the K-12 school year completed, Florida schools reported over 2,200 instructional positions still unfilled. Further, the vacancy with the greatest need was science. While schools were able to actively recruit to partially fill this gap, some schools had to hire substitute teachers (Isger, 2019). The effects of teacher attrition are profound and relate to overall instructional stability and student achievement.

SEFS strategically designs its PD workshops to re-spark the passion that new teachers had entering the profession.
In an anonymous post-PD workshop survey, a teacher wrote "...Thank you for the BEST professional development I have ever attended. The content was perfect for all grade levels and the scientists presenting were amazing. Everyone involved from the doctors to the grad students were so friendly and patient, and truly loved sharing their research with all of us novice teachers. I feel so rejuvenated and can't wait to go back to school and share what I learned with students and colleagues..." For many, PD opportunities look like creating unique and innovative experiences by taking teachers on paid experiences to field sites. Others may just seek additional content support to increase their teaching self-efficacy as it relates to science content. Another avenue is through the SEFS Facebook group where teachers communicate pedagogical or content concerns while peers and colleagues are able to provide feedback. Experts are also provided by SEFS to present at school district PD training sessions. Several school district leaders request scholars to lead sessions on up-to-date educational strategies.

Scientist in Residence. As a result of philanthropic support dedicated to counties in north-central Florida, SEFS has developed a partnership with the Marion County School District. The Marion County School District is mid-sized with 48 schools, of which 44 are Title 1 . The funding resulted in an opportunity to develop an innovative full-time Scientist in Residence program located at the Silver River Museum (2021), which is part of the Marion County public school district. The duties of the Scientist in Residence are quite broad and allow them to assist school districts in a variety of ways. Most of their time is spent working directly with teachers and students to develop lessons related to their curriculum. The close relationship with district officials allows the Scientist in Residence to follow the specific district's curriculum map, making each lesson as content-driven as possible. Outside of school visit outreach, there are many opportunities for professional development. The science lab at the Silver River Museum is home to lab equipment for a variety of fields, including chemistry and environmental science. The Scientist in Residence provides professional development involving potential lessons with this equipment, as well as in other content areas. The resident is not limited to the academic school calendar and can also participate in after-school activities and summer programming.

The Scientist in Residence program and COVID-19 allowed us to experiment with different content delivery systems. During the time that the schools were either fully or partially closed to in-person instruction, our Scientist in Residence conducted web-based virtual STEM learning to specific classrooms as well as combined presentations. The SEFS Scientist in Residence program resulted in a far greater reach in Marion County relative to other counties, while the virtual programming resulted in a better ability for us to 
scale up our reach (Figure 3). Now that we are transitioning to more in-person activities, we also are using the newly implemented science lab at the Silver River Museum for our programming which will include more active learning and hands-on activities (e.g., experiences related to local water quality).

\section{LOGISTICS}

The program has two K-12 education and outreach coordinators who were former K-12 teachers in Title 1 schools and bring this experience to the role. One of the coordinators worked in a charter school in Dallas, Texas while the other worked in a public school in Palm Beach, Florida, one of the largest school districts in the country. The coordinator's educational backgrounds include degrees in science and education which provide the tools and skills to promote the success of the program. The two coordinators' classroom experience covers middle and high school science and special education classrooms. Other Outreach programs would benefit from hiring coordinators with similar educational and experience prerequisites. The coordinators streamline and fully support the process of a scientist's classroom visit. By having outreach coordinators employed by the program, the burden and/or commitment of time, as well as K-12 pedagogical teaching expertise required by scientists, is greatly reduced (Andrews et al., 2005). The process of creating partnerships between teachers and scientists and preparing scientists for the classroom interaction is one of the primary roles of the coordinators. Those looking to build similar programs should consider partnering or networking with any current outreach programs in the area. The SEFS staff has been able to facilitate those outreach efforts, making such partnerships mutually beneficial.

The scientists in the current database were recruited in several ways. At the start of every academic year, the SEFS staff presents to various university departments and classes on who we are, what we do, and how we can support scientists in their Broader Impacts efforts (MacFadden, 2019). Also, our team has been able to leverage and develop partnerships with individuals that have outreach as part of their role and responsibilities (e.g., UF Institute of Food and Agricultural Sciences). Rather than starting from scratch, outreach programs achieve more by finding those already seeking to do outreach and facilitating those efforts for a mutually beneficial relationship. When scientists sign-up, a coordinator welcomes them and shares science communication resources to help prepare them for any future outreach. Offerings include a Canvas course (covering logistics, communication strategies, and recordings of past visits), infographics with tips and tricks to successful visits, opportunities to shadow visits prior to the one that they lead, and more. By not offering pre-written lessons, the scientist-teacher partnerships

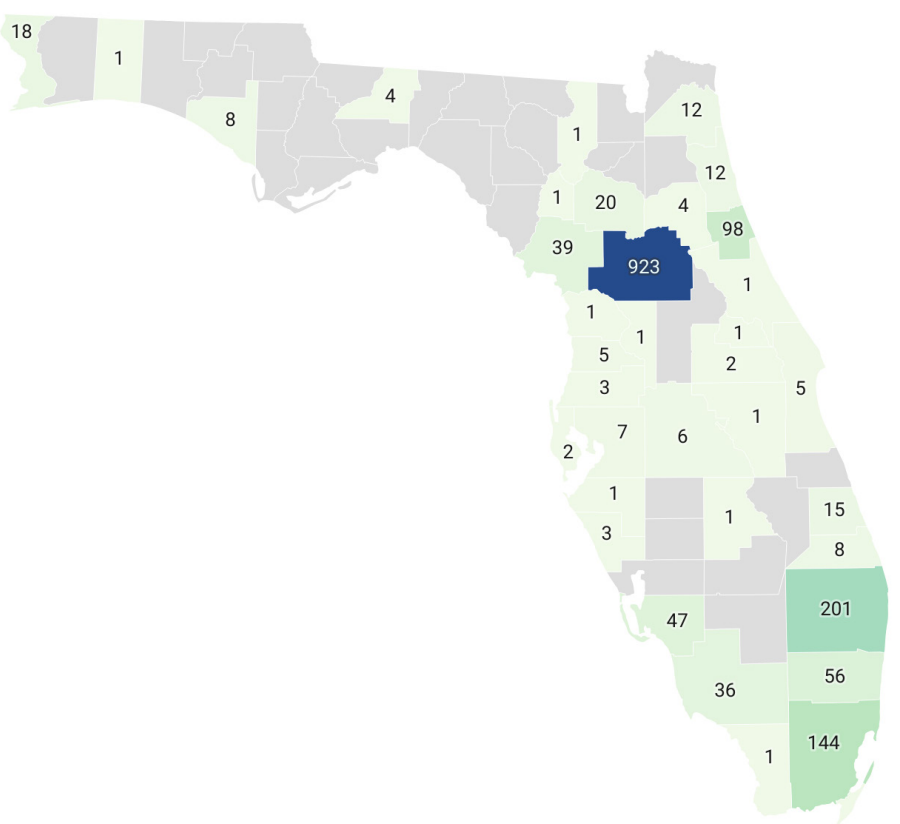

Figure 3. The number of completed scientist visits in Florida during the 2020-2021 school year.

are able to co-develop a plan that will be individualized for skill, (dis)abilities, and other factors to make the visit most impactful.

The scientist classroom visit request protocol follows a specific process. The coordinators have created a Google form that prompts the teacher for information about their vision for the visit. The requested details assist in the coordinators' identification of a scientist who will be the best match for the request. The scientist request form can be found on the SEFS website, Facebook group, monthly newsletter, Florida school district websites and promotional messages, and on the Florida Association of Science Teachers website (Florida Association of Science Teachers, n.d.). Once submitted, the coordinator who oversees that Florida county will confirm receipt of the request with the teacher and then begin reaching out to potential scientist participants. When a match is found, the coordinator will introduce the scientist and teacher to create a long-term scientist-teacher partnership. Included in the introduction email, both teacher and scientist receive an infographic with research-based best practices for a successful visit. The scientist receives a SEFS branded PowerPoint slide deck for use during the classroom interaction. Also, both parties involved will be encouraged to further discuss the details of the planned visit (including student prior knowledge, defining the learning standard, or other logistics). The email emphasizes keeping a coordinator copied on the emails so they can be kept aware of what is going on and support the visit at each step of the process. Additionally, if travel accommodations such as hotel and car rental are required, then a coordinator will arrange and pay 


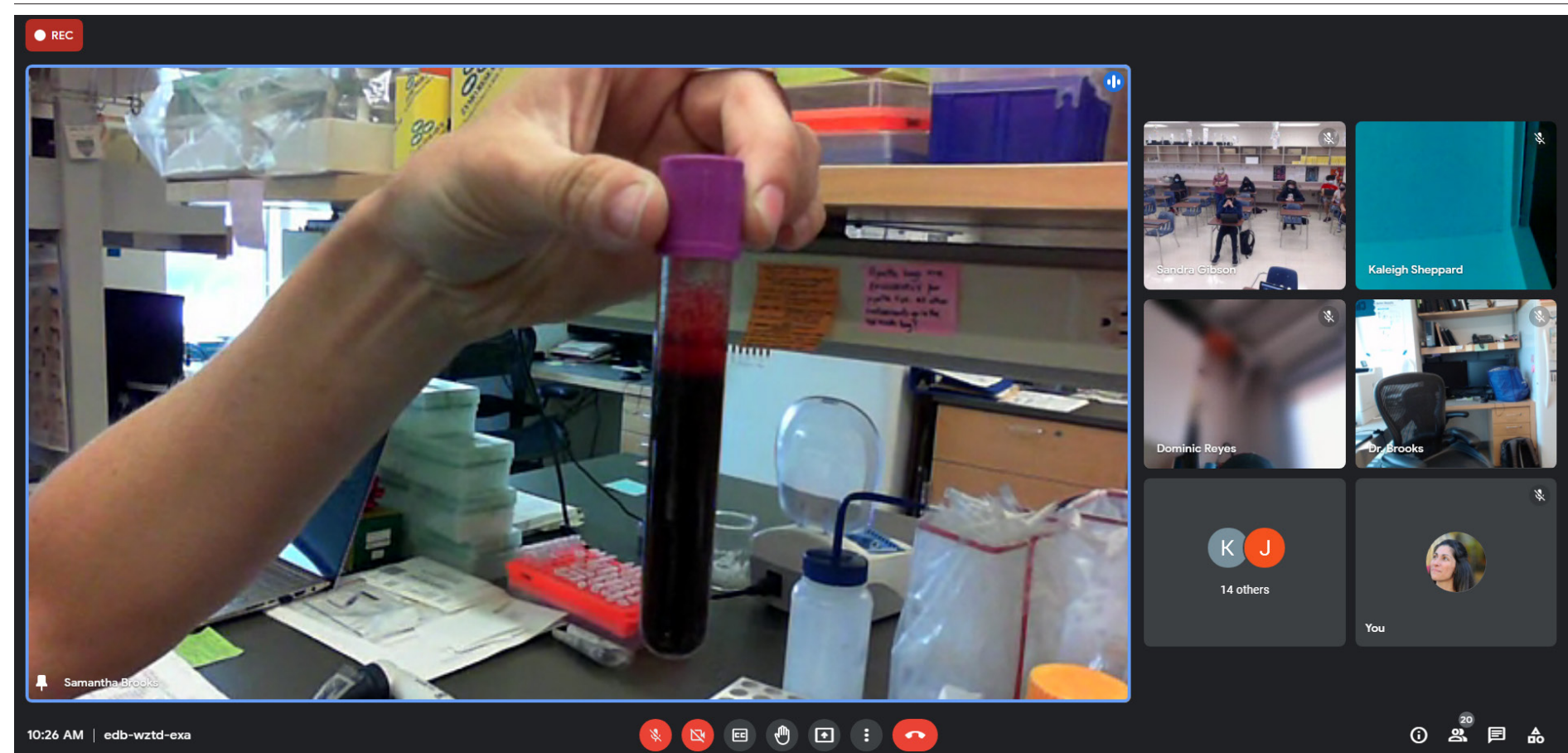

Figure 4. The UF Dr. Brooks Equine Genetics Lab demonstrates DNA extraction techniques for students across the state.

for the travel expenses.

After the completion of either the physical or virtual classroom visit, an electronic survey is distributed to the teacher to assess the quality of the program. The results indicate areas of success and possible areas to check in on with the scientists for continued science communication growth. The information provided also informs the coordinators if any changes need to be made during the scientist preparation and training phase. To continue building the program, coordinators may reach out to the teacher who completed the survey to use their text as a testimonial.

Innovative Classroom Visit Examples. During the past two years, the SEFS program has witnessed many positive classroom visit experiences both in-person and virtual in classrooms around the state. Visits are at the request of teachers who share content goals for an interaction with a scientist. Often, visits aim to connect the standard-aligned content being taught in the classroom with real-world scientist role models and real-world applications. A frequent outcome of the teacher-scientist collaboration is an ongoing relationship with the classrooms. Several examples of innovative classroom visits throughout Florida are illustrated as follows:

- Often, accessibility of lab equipment and supplies prevents teachers from offering authentic experiences for students that expose them to the tools and processes of science. Funding and lack of time can also be a deterrent for many teachers to provide field trip opportunities to their students as well (Tuthill and Klemm, 2002). As part of a genetics unit, teachers from a Title 1 high school in Palm Beach County wanted to expose their students to many of the common DNA techniques being used today to better understand inheritance. Students participated in a virtual field trip to the Brooks Equine Genetics Lab at UF. Their students watched the process of DNA extraction using horsehair and blood samples. Teacher Sandra Gibson remarked,

It's truly fascinating to see how this process has changed in the last 15 years since I worked in a lab myself. I learned so much about how bioinformatics has changed the speed and volume with which DNA is sequenced, and it's great to bring to light careers for my students.

During the interaction, Dr. Brooks and her graduate students also shared how artificial intelligence technology is being used to understand horse phenotypes for the horse racing industry. The visit gave students a chance to see the scientific process and common tools at use, the unpredictability of science, all while touring a lab at UF, somewhere that the Palm Beach group would be unable to visit normally due to the distance (Figure 4).

- As part of the Scientist in Residence program in April 2021, through a virtual boat ride a glass-bottom boat along the Silver River, our scientist reached 24 schools, 140 teachers, and 2,629 students. The glass-bottomed boats at the Silver Springs State Park are specifically designed to allow perfect viewing of the springs down below but provide limited occupancy for patrons. Capacity, as well as other obstacles, have made field trips on the glass-bottom boats a logistical and financial challenge 
for schools. In collaboration with the Silver Springs State Park, we were able to create a virtual glass-bottom boat tour for all K-5 Marion County students to enjoy. The experience was achieved by placing a camera on the glass itself, allowing the boat captain to share the rich history of the river, and letting the scientist explain what life is being shown through the glass. Exposing students to science in a tangible way shows them how interconnected science concepts can be to each other and the student themselves (Raved and Assaraf, 2010). For example, along the boat ride, students were introduced to the Florida aquifer and water cycle, the damage pollution has on their local waterways, invasive species, and even some of the research being conducted in that area. Rather than reading about Earth systems topics in a textbook, they saw how science plays out in the real world. A Marion County elementary school teacher said,

Thank you for a great year of field trips! My students were very interested in what they could do to help and repeatedly asked if they could come clean up the river. They stayed on the edges of their seats and were sponges, absorbing everything they could.

- When a Duval County teacher was challenged to continue creating authentic science experiences for her students, she reached out to SEFS for support. Feeling nervous and unprepared to lead some activities on her own, she was hoping for a scientist to share their expertise. By establishing a teacher-scientist partnership, teachers can receive assistance which enables them to conquer their hesitations surrounding teaching certain content areas (Ufnar and Shepherd, 2018). After two weeks of collaborations and co-developing a lesson, the teacher and scientist began their classroom interaction. Although the visit was virtual due to COVID-19 restrictions, the 10 fourth-grade students were able to participate in an authentic hands-on experience just as they would with the scientist in the room. With the support of personal tablets, the scientists (in Tallahassee) and the students (in Jacksonville) were able to synchronously dissect squid specimens "together." After reflecting on the experience, Florida State University's Sea to See program scientist Bill Turner shared,

Thank you both for giving us a chance to dissect squid with this wonderful class. Kim is obviously a fantastic teacher as evidenced by her student's knowledge, engagement and the classroom culture of inquisitiveness. We had such a good time with this. Today I could see the smiles behind our masks everywhere I looked (Figure 5).

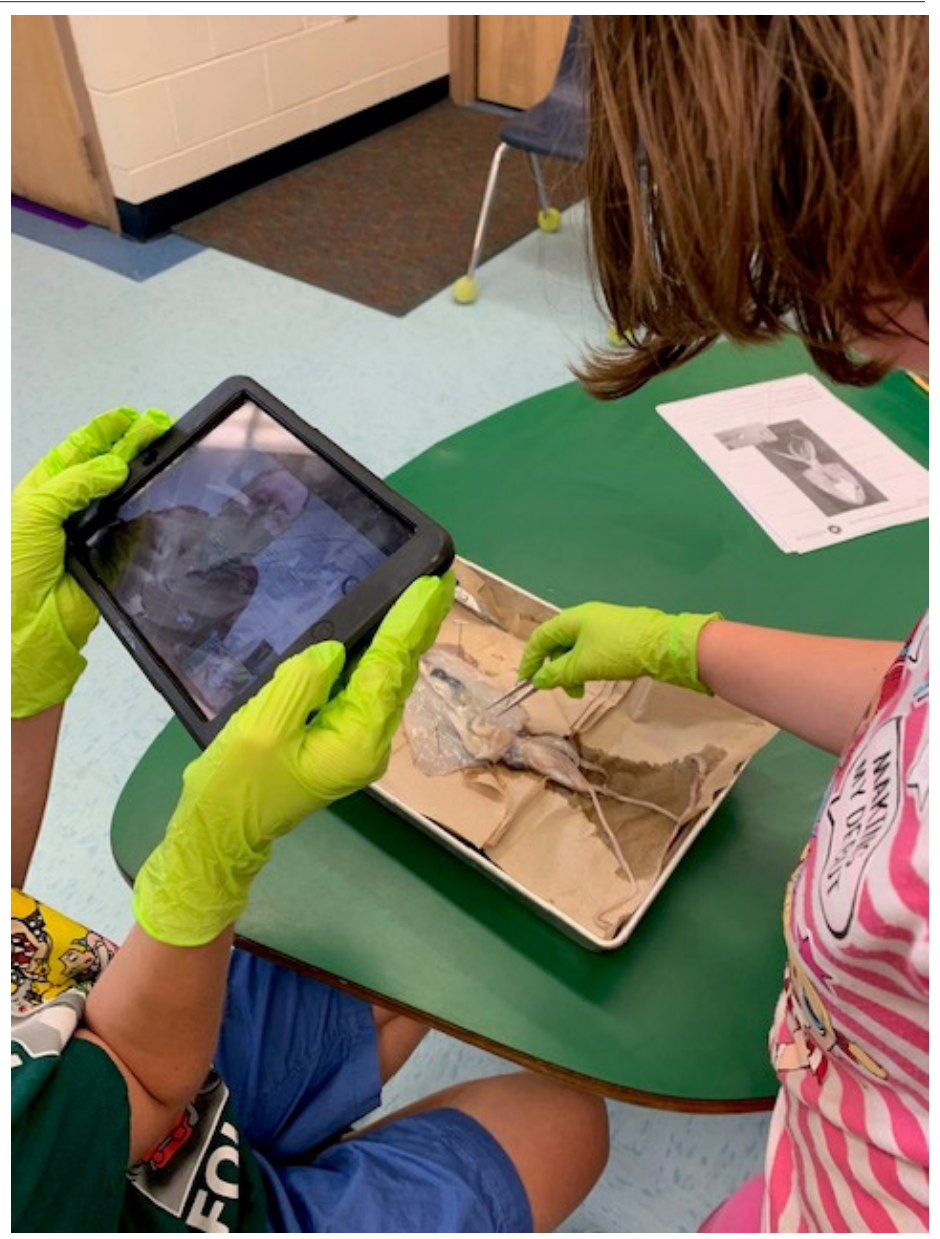

Figure 5. Sea-to-See Scientist Bill Turner virtually dissects squid with Duval County students.

Funding and Business Model. The SEFS program was established through a four-year-long moonshot grant funded by the UF President's Office in 2018. SEFS was initially proposed to be a small pilot in three Florida counties that quickly grew to five, and after COVID-19 hit, the SEFS program expanded the number of counties that we have reached to almost three dozen by early 2021. Given the rapid expansion, the base level of support was quickly outgrown. Thus, to reach our current level of effort and to increase capacity, we have added to our funding stream. This mostly includes matching and other funds from other UF stakeholders (Provost, VP for Research, and Museum Director's Office), income generated from a TESI endowment, and philanthropic gifts from private donors. The salaries of the three faculty in the TESI core team are contributed as a match from the Museum's annual budget appropriations.

Our long-term business model is to offer our programs free of charge to the teachers and schools, with the staff salaries and operating expenses derived from the funding sources described above. We are also promoting the program as one that can help scientists who submit proposals to federal grant agencies with a K-12 component of their Broader Impacts plan (MacFadden, 2019), and in so doing, include 
salary for our SEFS coordinators' efforts written into the scientists' budgets. We also plan to provide program evaluation services as a cost-generating measure to generate revenue back to sustain SEFS. Ultimately, we are planning to fully sustain the base level of operations via state support. Using these combined strategies, we envision SEFS and TESI core programs that are resilient and financially sustainable.

Evaluation and Data Collection. Evaluation of the efficacy of the program to engage program participants in the teacher-scientist partnership is accomplished using the custom-designed Scientist-Teacher Educational Partnership Survey (STEPS, Appendix A). STEPS consists of about 10 items that are completed independently by both the teacher and the scientist. The two factors - Communication and Planning and Science Teaching Self-Efficacy - help the scientist and the teacher partners independently reflect on the important aspects of the partnership experience. As of the time of this publication, 48 SEFS participants completed the STEPS survey. Thirty-eight of them were teachers, 10 were scientists. 37 identified as female, 7 as male, and 4 did not wish to provide this information. The ethnic and racial identity reported in this sample consisted of primarily White respondents $(\mathrm{n}=30)$, Black or African American respondents $(n=5)$, Asian respondents $(n=2)$, Other/not listed $(n=4)$, and respondents who did not wish to provide $(\mathrm{n}=7)$. Currently, at least $93 \%$ of the teacher and scientist respondents either agree or strongly agree that a) the communication between the partners was timely and helpful and b) they are learning new and useful strategies for planning and implementing science instruction.

Once SEFS collects an adequate number of teacher and scientist STEPS survey data, we will perform a confirmatory factor analysis to determine whether the items load onto the two factors that underlie the survey design. Given the number of items in the STEPS survey, a conservative estimate for the number of respondents needed to perform a robust confirmatory factor analysis is 200 (Wolf et al., 2013).

Barriers, Challenges, and Lessons Learned. The global COVID-19 pandemic has been a major factor affecting our SEFS programming and outreach. Thus, in March 2020, all in-person classroom visits and university travel were closed down and largely remained that way through July 2021. The SEFS team, therefore, quickly adapted by changing the presentation format of all of the programming to virtual delivery, whether it be multi-class presentations, single classroom virtual visits, or teacher PD.

We have learned many things from COVID-19, for example: (1) SEFS can remain active and in high demand regardless of whether the programming is virtual or in-person and (2) the program's reach extends to many more classrooms virtually (Figure 7). The virtual delivery is done primarily via Zoom, but accommodations can be made for other platforms, such as Microsoft Teams and Google Meet, depending upon the needs of the particular school district.

Further, SEFS staff needed to provide additional technical support to Florida teachers. The sudden switch to virtual and/or hybrid teaching shifted pedagogical and classroom management demands. Both districts and teachers

\section{My partner and I developed shared goals and experiences}

Questions and concerns I had during planning were adequately discussed

Communication between me and my partner was timely

Quality of communication between me and my partner was adequate

Amount of communication between me and my partner was adequate

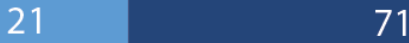

$23 \quad 73$

$21 \quad 75$

$21 \quad 71$

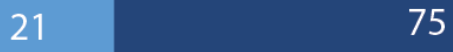

25

50

75

Percent

\section{Disagree strongly Disagree Agree $\square$ Agree strongly}

Figure 6. Data collected from Scientist Teacher Educational Partnership Survey (STEPS - Appendix A). 


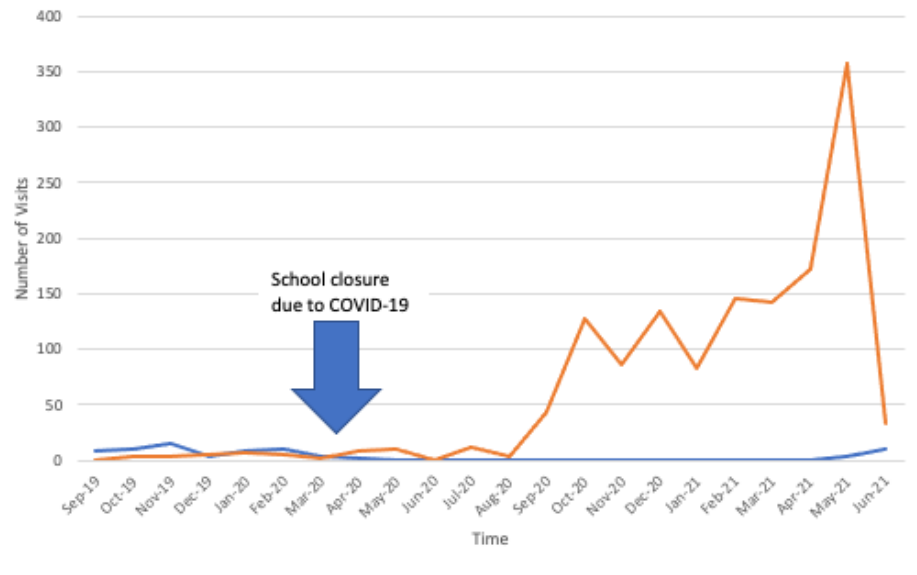

Figure 7. The number of completed visits from the onset of the SEFS program to the present.

quickly realized that the huge alteration to teaching could be a barrier to student learning. Additionally, outside educational agencies and organizations that customarily hosted K-12 field trips were, in effect, grounded from outreach. Because of SEFS's established virtual platform, some agencies looked to SEFS to partner and collaborate to deliver content. Thus, even during COVID-19, the demand for SEFS programming remained high, and is indeed ever-increasing throughout Florida.

While there is no substitute for the in-person classroom experience for the scientists, teachers, or students, the move to a virtual platform has greatly increased the ability for SEFS to reach a greater number of K-12 audiences. From a strategic perspective, it has allowed the program to better understand how to be a resilient organization. The pivot to virtual engagement increased reach and demonstrates the scalability of SEFS programs using virtual resources.

\section{Recommendations for Science Outreach Programs.}

A major recommendation for others looking to replicate a similar program to SEFS would be hiring coordinators, particularly former teachers, whose main responsibility is the facilitation of outreach programs. Having dedicated staff to coordinate and facilitate the scientist classroom visits limits the administrative burden on scientists and teachers. Since scientists do not need to organize the interaction, they can focus their time and energy on going through the SEFS training, planning their presentation, or practicing to make sure they are ready. Similarly, teachers are challenged to use any available time that they have most effectively. One Florida teacher communicated to the coordinators that before SEFS, between grading, lesson planning, connecting with parents, and more, it was too difficult to find the necessary time to arrange all aspects of a visit on their own. Although the teacher wanted to create special experiences for students, they were unable to make them happen. As a result, if the resources allow, programs should hire or allocate a staff member to oversee the outreach process.

Another recommendation is to establish an organized database of scientists and teachers as well as a system to collect important metrics (such as grade level, topics, number of students reached, etc.). The latter also extends to implementing surveys for post-visit feedback and testimonials for promotional purposes that help the program grow. Further, an emphasis should be placed on relationship building between the scientist and teacher to create a mutually beneficial partnership. Both parties need to be comfortable with the process and not feel that participating is a daunting task. The program should therefore push out reminders, checkins, and provide feedback to both the scientist and teacher. Both the teacher and scientist should also be given best practices and ideas for engagement and successful interactions.

Finally, all aspects of communications should be prioritized to ensure that the visit occurs effectively. More specifically, planning items may include creating training for the scientists to cover research-based science communication tips and connecting with the teacher to discuss logistics and the teacher's goal and vision for the visit (UF Thompson Earth Systems Institute, 2020; UF Thompson Earth Systems Institute, 2019). Although the SEFS program offers a training course on Canvas, it may be adapted or extended to other platforms as it makes sense for the specific target audience. The training aims to address scientist's frequently asked questions, including specific topics to cover during the presentation, how often to communicate with their teacher counterpart, each party's role, and more. By sharing clear information and communication from the beginning, these best practices will optimize the success of the partnerships and programs.

\section{CONCLUSIONS}

Currently, in its second year of implementation, the SEFS program pilot has reached over 53,000 students during about 1,700 scientist classroom interactions involving over 850 teachers. The project holds promise as its efforts continue to grow with additional interested district leads, teachers, scientists, and as we continue to develop a sustainable funding model for the future. Our program tailors lessons and activities based on the individual needs of the teachers and their classrooms. The customization and direct collaboration between teacher and scientist are unique to the program and create a special experience for all parties involved.

Since the project is still in its first few years since inception, a limitation of the project is that there has not been a wide response in the evaluative efforts thus far. We realize that is a current shortcoming if we want to truly understand the impact that we are making on our teachers and their students. An IRB-approved STEP (Scientist-Teacher Ed- 
ucational Partnership survey) is in the beginning stages of implementation. The survey is designed to explore teachers' and scientists' perceptions of their partnership in designing and implementing instruction. It focuses on communication and planning, science teaching self-efficacy, and perceptions of student engagement and learning. Once additional responses are collected, an assessment will analyze the impact of the scientist-teacher relationships. Further, SEFS coordinators are developing plans with research partners to measure impact on student academic growth from participating classrooms as a result of SEFS intervention efforts.

Overall, we have learned many lessons and developed best practices over the first two years of SEFS. Over the next several years we will continue to refine programs to be grounded in student-centered learning and develop a sustainable funding model for the future. In doing so, we will be able to scale up and reach more schools, teachers, and students in Florida's public schools, and ultimately be able to demonstrate impact. We envision that SEFS's activities will result in a better educated next generation of Floridians better poised to act responsibly in the 21 st century, particularly as related to the future of the Earth and its natural systems.

\section{ASSOCIATED CONTENT}

Supplemental material mentioned in this manuscript can be found uploaded to the same webpage as this the manuscript.

\section{AUTHOR INFORMATION Corresponding Author}

Brian Abramowitz. University of Florida. 3215 Hull Road, Gainesville, FL, 32611. Babramowitz@floridamuseum.ufl. edu

\section{Author Contributions}

The manuscript was written through contributions of all authors. All authors have given approval to the final version of the manuscript.

This work is licensed under a Creative Commons Attribution 4.0 International (CC BY 4.0) License.

\section{ACKNOWLEDGMENTS}

We would like to thank Florida teacher, student, and scientist participants for their contributions and support.

\section{FUNDING SOURCES}

This material is based upon work supported by the University of Florida, Felburn, and Smallwood foundations.
Any opinions, findings, and conclusions or recommendations expressed in this material are those of the author(s) and do not necessarily reflect the views of the funders.

\section{ABBREVIATIONS}

DEAI: Diversity, Equity, Accessibility, and Inclusion; PCK: Pedagogical Content Knowledge; PD: Professional Development; SEFS: Scientist in Every Florida School; STEM: Science, Technology, Engineering, and Math; STEPS: Scientist-Teacher Educational Partnership Survey; TESI: Thompson Earth Systems Institute; UF: University of Florida

\section{REFERENCES}

Andrews, E., Weaver, A., Hanley, D., Shamatha, J., and Melton, G. (2005). Scientists and public outreach: Participation, motivations, and impediments. Journal of Geoscience Education, 53(3), 281-293.

Bates, C. C., and Morgan, D. N. (2018). Seven elements of effective professional development. The Reading Teacher, 71(5), 623-626. https://doi.org/10.1002/trtr.1674.

Bay Area Scientists Inspiring Students. (n.d.). Community Resources for Science. Retrieved April 19, 2021, from https:// crscience.org/educators/basis/

Brinkley, D. (2019). American moonshot: John F. Kennedy and the great space race. Harper.

Brown, J. C., Bokor, J. R., Crippen, K. J., and Koroly, M. J. (2014). Translating current science into materials for high school via a scientist-teacher partnership. Journal of Science Teacher Education, 25(3), 239-262. https://doi. org/10.1007/s10972-013-9371-y

Burton, R. (2019, December 2). Florida teacher discovers 5-million-year-old horse tooth during Scientist in Every Florida School fossil dig. Thompson Earth Systems Institute. https://www.floridamuseum.ufl.edu/earth-systems/blog/ florida-teacher-discovers-5-million-year-old-horse-toothduring-scientist-in-every-florida-school-fossil-dig/

Callaway, E. (2011). Fossil data enter the web period. Nature, 472, 150. https://doi.org/10.1038/472150a

Darling-Hammond, L., Hyler, M. E., and Gardner, M. (2017). Effective teacher professional development. Learning Policy Institute. https://files.eric.ed.gov/fulltext/ED606743.pdf

Elewa, A. M. T. (2011). Computational paleontology. Springer.

Ennes, M., Lawson, D. F., Stevenson, K. T., Peterson, M. N., \& Jones, M. G. (2021). It's about time: perceived barriers to in-service teacher climate change professional development. Environmental Education Research, 1-17. 
Florida Association of Science Teachers. (n.d.) Florida Association of Science Teachers. https://fastscience.wildapricot.org/

García, E., and Weiss, E. (2016, April 16). U.S. schools struggle to hire and retain teachers: The second report in 'The Perfect Storm in the Teacher Labor Market' series. Economic Policy Institute. https://www.epi.org/publication/u-s-schoolsstruggle-to-hire-and-retain-teachers-the-second-report-inthe-perfect-storm-in-the-teacher-labor-market-series/

Hahn, E. R. (2021). The developmental roots of environmental stewardship: Childhood and the climate change crisis. Current Opinion in Psychology. https://doi.org/10.1016/j. copsyc.2021.01.006.

Herrington, D. G., Bancroft, S. F., Edwards, M. M., and Schairer, C. J. (2016). I want to be the inquiry guy! How research experiences for teachers change beliefs, attitudes, and values about teaching science as inquiry. Journal of Science Teacher Education, 27(2), 183-204. http://dx.doi. org/10.1007/s10972-016-9450-y

Isger, S. (2019, January 19). Teacher shortage: Palm Beach County elementaries feeling the pinch. The Palm Beach Post. https://www.palmbeachpost.com/news/20190119/ teacher-shortage-palm-beach-county-elementaries-feeling-pinch.

Kahan D.M. (2012) Cultural cognition as a conception of the cultural theory of risk. In: Roeser S., Hillerbrand R., Sandin P., Peterson M. (Eds.) Handbook of Risk Theory. Springer, Dordrecht. https://doi.org/10.1007/978-94-007-1433-5_28

Kavenuke, P. S. (2013). What is it that keeps good teachers in the teaching profession: A reflection on teacher retention. Academic Research International, 4(1), 165-175.

Komoroske, L. M., Hameed, S. O., Szoboszlai, A. I., Newsom, A. J., and Williams, S. L. (2015). A scientist's guide to achieving broader impacts through K-12 STEM collaboration. Bioscience, 65(3), 313-322. https://doi.org/10.1093/ biosci/biu222

Letters to a Pre-Scientist. (n.d.). Program Information. Retrieved April 19, 2021, from https://www.prescientist.org/ for-teachers/penpalprogram/

MacFadden, B. (2019). Broader Impacts of Science on Society. Cambridge: Cambridge University Press. doi:10.1017/9781108377577

Marincola, E. (2006). Why is public science education important? Journal of Translational Medicine, 4(1), 7.

Menon, D., and Sadler, T. D. (2016). Preservice elementary teachers' science self-efficacy beliefs and science content knowledge. Journal of Science Teacher Education, 27(6), 649-673.

National Research Council (2012). A framework for K-12 science education: Practices, crosscutting concepts, and core ideas. Washington DC: National Academy of Science.

National Research Council (2014). STEM integration in K-12 education: Status, prospects, and an agenda for research. Washington DC: National Academy of Science.
NCES. (2021). Fast Facts: Title 1. National Center for Education Statistics. Retrieved April 20, 2021 from https://nces. ed.gov/fastfacts/display.asp?id=158.

Oliphant, T. (2019). Book review of American Moonshot: John F. Kennedy and the Great Space Race by Douglas Brinkley, Retrieved April 19, 2021.

Park, S., and Oliver, J. S. (2008). Revisiting the conceptualisation of pedagogical content knowledge (PCK): PCK as a conceptual tool to understand teachers as professionals. Research in Science Education, 38(3), 261-284.

Peterson, M. N., Stevenson, K. T., and Lawson, D. F. (2019). Reviewing how intergenerational learning can help conservation biology face its greatest challenge. Biological Conservation, 235, 290-294. https://doi.org/10.1016/j.biocon.2019.05.013.

Plumley, C. L. (2019). 2018 NSSME+: Status of elementary school science. Horizon Research, Inc. http://horizon-research. com/NSSME/wp-content/uploads/2019/05/2018-NSSME-Status-of-Elementary-Science.pdf

Raved, L., and Assaraf, O. B. Z. (2011). Attitudes towards science learning among 10th-grade students: A qualitative look. International Journal of Science Education, 33(9), 12191243.

School. (n.d.). Florida Department of Education. Retrieved April 20, 2021, from http://www.fldoe.org/accountability/data-sys/edu-info-accountability-services/pk-12-publicschool-data-pubs-reports/school/index.stml

SEFS (Scientist in Every Florida School). 2021. https://www.floridamuseum.uff.edu/earth-systems/scientist-in-every-florida-school/, accessed April 20, 2021.

Shein, P. P., and Tsai, C. Y. (2015). Impact of a scientist-teacher collaborative model on students, teachers, and scientists. International Journal of Science Education, 37(13), 21472169. https://doi.org/10.1080/09500693.2015.1068465

Silver River Museum. (2021). https://silverrivermuseum.com/, Retrieved May 26, 2021.

Skype a Scientist. (2021). https://www.skypeascientist.com/, Retrieved April 29, 2021.

Sparks, S. D. (2018). Which teachers are most likely to leave school mid year? Education Week, https://www.edweek. org/leadership/which-teachers-are-most-likely-to-leaveschool-mid-year/2018/08, Retrieved May 21, 2021.

Spence, C. (2019). Science class: Connecting scientists with teachers and students. UF Explore, 24(2):25-27.

Stevenson, K. T., Peterson, M. N., Bondell, H. D., Moore, S. E., and Carrier, S. J. (2014). Overcoming skepticism with education: Interacting influences of worldview and climate change knowledge on perceived climate change risk among adolescents. Climatic Change, 126, 293-304. doi:10.1007/s10584-014-1228-7. 
Sergent, J. (2020, September 10). Learning pods help kids bridge social divide. USA Today. https://www.usatoday.com/ in-depth/news/2020/09/10/learning-pods-what-they-andhow-set-one-up/3435956001/, Retrieved April 5, 2021.

Tanner, K. D. (2000, April). Evaluation of scientist-teacher partnerships: Benefits to scientist participants. In National Association for Research in Science Teaching Conference Paper, New Orleans, LA, April.

TESI. (2021). Thompson Earth Systems Institute, https://www. floridamuseum.ufl.edu/earth-systems/, Retrieved April 18, 2021

Tuthill, G., and Klemm, E. B. (2002). Virtual field trips: Alternatives to actual field trips. International Journal of Instructional Media, 29(4), 453.

Ufnar, J. A., Bolger, M., and Shepherd, V. L. (2017). A retrospective study of a scientist in the classroom partnership program. Journal of Higher Education Outreach and Engagement, 21(3), 69-96. https://openjournals.libs.uga.edu/ jheoe/article/view/1347

Ufnar, J. A., and Shepherd, V. L. (2020). The magic in the classroom: A twenty-year sustained scientist in the classroom partnership program. Journal of STEM Outreach, 3(3), $1-15$.

Ufnar, J. A., Lee, C., and Shepherd, V. (2018). The Vanderbilt scientist in the classroom partnership: A novel collaborative apprenticeship model for situated professional development. Journal of STEM Outreach, 1(2), 78-92.

UF Thompson Earth Systems Institute. (2020, October 23). SEFS Scientist communication tips. YouTube. https://www.youtube.com/watch? $\mathrm{v}=$ TqdsstSK $8 \mathrm{t} 0$.

UF Thompson Earth Systems Institute. (2019, October 1). How to sign up for the SEFS program. YouTube. https://www. youtube.com/watch?v=PiPaF-Dsv4c\&feature=youtu.be

Welcome to CPALMS. (2019). CPALMS. Retrieved April 18, 2021, from https://www.cpalms.org/

Wolf, E. J., Harrington, K. M., Clark, S. L., and Miller, M. W. (2013). Sample size requirements for structural equation models an evaluation of power, bias, and solution propriety. Educational and Psychological Measurement, 73(6), 913-934. 